\title{
Peer support programs for people experiencing suicidality - A systematic scoping review of current literature
}

MARISA SCHLICHTHORST ( $\sim$ marisa.schlichthorst@unimelb.edu.au )

The University of Melbourne School of Population and Global Health https://orcid.org/0000-00032627-7238

Ingrid Ozols

Mental Health at Work

Lennart Reifels

The University of Melbourne School of Population and Global Health

Amy Morgan

The University of Melbourne School of Population and Global Health

Research article

Keywords: Peer-support, suicide, suicide prevention, literature review, scoping review

Posted Date: October 31st, 2019

DOI: https://doi.org/10.21203/rs.2.16656/v1

License: (c) (i) This work is licensed under a Creative Commons Attribution 4.0 International License. Read Full License 


\section{Abstract}

Background Peer-led support models have gained increasing popularity in mental healthcare. Yet little is known about the types of peer support programs that exist in suicide prevention and whether these are effective in improving the health and wellbeing of people at risk of suicide.

Method We conducted a systematic scoping review, involving a search of three academic (Medline, PsycINFO, Embase), and selected grey literature databases (Google Scholar, WHO Clinical Trials Registry) for publications between 2000 and 2019. We also contacted suicide prevention experts and relevant internet sites to identify peer support programs that exist but have not been evaluated. The screening of records followed a systematic two-stage process in alignment with PRISMA guidelines.

Results We identified 8 records accounting for 7 programs focused on peer-led support programs in suicide prevention. These programs employed a range of different designs and included a variety of settings (schools, communities, rural and online). Only 4 of these 7 programs contained data on the effectiveness of the program, and this evaluation data was descriptive on all accounts but showed promising results. With the small number of eligible programs in this review our findings are limited and must be interpreted with caution.

Conclusions Despite the increased focus of policymakers on the importance of peer support programs in suicide prevention, our scoping review confirms an evidence gap in research knowledge regarding design, implementation, and effectiveness of programs. More rigour is required in reporting peer support initiatives to clarify the underlying definition of peer support and to enhance our understanding of the types of current peer support programs available to those experiencing suicidality. Further, we need formal and high-quality evaluations of peer support suicide prevention programs to better understand their effectiveness on participant health across different settings and delivery modalities and to allow for comprehensive systematic reviews and meta-analysis in future.

\section{Background}

Peer support is a subjective and context specific relationship which is based on lived experience, sharing common life experiences, circumstances, situations and values (1). It is generally viewed as a "system of giving and receiving help, founded on key principles of respect, shared responsibility and mutual agreement of what is helpful" (2). This mutual experience creates a deep, holistic understanding where people are able to 'be' with each other, without the constraints of a hierarchical (expert/patient) relationship (2) and can focus on the understanding of another's situation empathically through the shared experience of emotional and psychological pain which can aid recovery (3). Peer support programs have been shown to offer alternative support options in crisis and care, and an effective strategy to engage with people that traditional health services fail to reach (4).

First mentioned in the late $18^{\text {th }}$ century in the context of inpatient care (5) peer support has increasingly been documented since the ex-patient/psychiatric survivor movement in the 1970s (6). Aiming to address 
restrictive psychiatric and mental health care models, the movement advocated for mutual support, userled activities, reduction of marginalisation and stigma and civil rights for mental health patients (7). As such the interest in peer support by health care services and research was first focussed on mental health conditions and in line with a greater focus on recovery-based and consumer-focussed care in mental health (3). Since the early 1990s support has come from government and policy agencies and advocacy groups for building a peer support workforce in health care across a broad range of health conditions (810). As such, peer-led support programs both in community and services settings have steadily grown since then and some evidence of their effectiveness has emerged (11). Literature demonstrates that peer support can improve empowerment and hope for recovery for people with severe mental health conditions $(12,13)$, and reduce mental health symptoms for those individuals with severe mental health conditions (e.g. schizophrenia and clinical depression) and for those in clinical settings (14).

Despite the growing prominence of peer-led support models in mental healthcare, little systematic information is available today about what types of peer support models exist in suicide prevention and whether these are effective. The little existing information has largely been focussed on postvention programs and people bereaved by suicide. Summarised in recent literature reviews, mostly positive evidence for peer support programs in reducing grief symptoms, psychosocial and suicide related outcomes, and increasing personal growth and well-being in bereaved suicide survivors has been found (15-17). While types of peer-support programs varied, the matching of similar experiences between the support person and the recipient has been found to be an important enabler of effective bereavement peer support programs (16).

To our knowledge no systematic review has been conducted investigating peer support programs for people experiencing suicidality. Addressing this gap, we undertook a scoping review of literature on suicide prevention peer support programs and interventions with a focus on reducing suicidality in individuals and supporting recovery from suicidality. Our aim was to identify what types of peer-led suicide prevention support programs exist and investigate whether these have been evaluated on their effectiveness to reduce suicide risk. For this review we adapted the general definition of peer support (provided above) for the context of suicidality. Namely, support needed to be delivered by peers with a lived experience of suicide, meaning experiencing suicidality or having personal history of suicidality.

\section{Methods}

This scoping review was designed following a methodological framework for scoping studies developed by Arksey \& O'Malley's in 2005 and further revised by Levac et al. in $2010(18,19)$. The review process followed the recommended five stages: identifying the research question; identifying relevant studies; selecting studies; charting the data; and collating and summarising findings. We included key stakeholder consultations as part of our grey literature search strategy, which is described in detail below.

This review was conducted in accordance with the PRISMA recommendations for systematic reviews (20) and the review protocol was registered with PROSPERO (CRD42018109620). 


\section{Identifying the research question}

A research team was convened consisting of three research experts in suicide prevention (MS, AM, LR) and one researcher with lived experience and advocacy and consultancy roles in mental health and suicide related peer-support (IO). Using a co-design methodology, the team met to discuss the purpose of the review and was guided by IO's experience in the peer support sector of suicide prevention in developing the review protocol and research questions $(21,22)$.

Two broad exploratory research questions were developed: What types of suicide prevention peer-support programs delivered by people with lived experience currently exist? What do we know about their effectiveness? These broad questions allowed us to generate an overview of research undertaken on this topic.

\section{Identifying relevant studies}

We undertook a systematic search for peer reviewed articles, a search of grey literature databases, and a website search and expert consultations to identify eligible programs. A systematic search of the literature was conducted for articles published between 2000 and 2019 using Medline (PubMed), PsycINFO (OVID interface), and EMBASE (OVID interface). Bibliographies of previous systematic reviews and included papers were also searched. Grey literature was searched to include research that had not been peer-reviewed, including Google Scholar and the World Health Organization (WHO) Clinical Trials Registry (limited to a 5-year period from 2013-2018). To identify existing suicide prevention peer support programs, we also approached clinical and academic content experts and searched relevant internet sites including organisations known to be active in suicide prevention. See Additional Material $1 \mathrm{for}$ a list of identified and screened websites and programs.

Search terms were developed relating to the three key concepts underpinning the literature review: suicide, peer support and lived experience. Alternative terms for peer support were developed and refined during iterative test searches. The final search strategy was developed using medical subject headings and free text words related to peer support and suicide prevention. Search terms were adjusted to fit the requirements of different databases. A complete list of search terms by database is available in Additional Material 2.

\section{Study selection}

All records were imported into Endnote (version X8.2) and screened for inclusion in two stages. In the first stage, one researcher (AM) screened titles and abstracts for potential inclusion. In stage 2 , the full texts of retrieved articles were screened independently by two researchers (AM and MS). Discrepancies were resolved in a meeting between the two researchers. Google Scholar records were screened first by title and abstract and then by full text by MS. WHO Clinical Trials Registry entries were screened by LR. Grey 
literature was retrieved by 10 via internet search and consultations with experts in the area and then screened for inclusion in a team meeting by IO, LR, MS and AM.

Records were eligible if they included a peer-support program with a focus on suicide prevention for people who experience suicidality in some form. Peer supporters had to have lived experience of suicide; they could be community volunteers, people with similar experiences, or health professionals/ health care staff if they had a lived experience of suicide and this informed their support role as peer supporter. Our review was not restricted to programs with matched lived experiences. There were no restrictions on the delivery mode of the programs; for example, programs could be delivered one-on-one, in group settings, as telephone support, online, at home, or in respite care.

We excluded records if programs were not delivered by people with a lived experience of suicide; were suicide bereavement programs; were capacity building programs such as gatekeeper training, suicide awareness raising or suicide literacy programs; were focussed on improving mental health more broadly; or were a minor component of a multi-component intervention and the effect of peer-support could not be distinguished from the larger program.

Articles in academic databases and Google Scholar had to be published between January 2000 and August 2019 and trials had to be registered on the WHO Clinical Trials Registry between 2013-2018. Academic databases were first searched on 14 June 2018. A second search of the academic databases was run on 29 August 2019 after the authors became aware of new evidence published since the original search. Google Scholar was searched on 21 June 2018 and the Trial Registry was searched on 7 September 2018. There was no time restriction on programs and records identified through expert consultation and web searches. We included any evaluation reports of eligible programs, irrespective of study design, setting, participant age, and publication language, so long as they could be translated into English. The Flow Diagram in Figure 1 includes the number of records at each screening stage for all data searches and data sources combined.

Following these criteria, we identified 4,077 records through electronic searches and 408 through searching other sources including grey literature, websites and expert consultations. Following removal of duplicates, 3,058 records were screened by title and abstract information. This led to the exclusion of 2,925 records. The remaining 133 records were read in full text by AM and MS who reached consensus on the final inclusion of 8 records according to the selection criteria. Of these 8 records, two referred to the same program, and were therefore summarised as one program in the results section.

Figure 1: Flow diagram illustrating the literature search process

\section{Charting the data}

Records identified for final inclusion were extracted into a charting table which documented the following information: Reference, title and country of the program; program description including setting modality 
and lived experience mode; study aim and methodology; sample characteristics and key findings (if the program had been evaluated). Table 1 lists details on all identified programs.

\section{Collating and summarising findings}

The information in the charting table was then synthesised in accordance with the two research questions of this paper. Due to the variation in study design and the absence of evaluation data for many identified programs we focussed on a narrative summary of studies. First, we provide an overview of the types of peer support suicide prevention programs (research question 1) by briefly summarising programs by their setting, modality and the role of lived experience. Secondly, for those programs that had been evaluated we characterise the study aim and methodology and discuss key findings regarding the effectiveness for suicide prevention (research question 2).

\section{[Table 1 about here]}

\section{Results}

\section{Types of suicide prevention peer support programs}

Our search identified eight records that fulfilled the inclusion criteria. These described seven programs that were from four different countries: USA (3), Germany (2), China (1), and Australia (1), and which varied in setting and design (see Table 1). Of the seven programs, four included an evaluation component $(23-27)$ and three provided descriptive accounts of a program (28-30). Four peer support programs provided group support $(23-26,29)$, two were designed to deliver one-on-one support $(27,28)$ and one program included mixed modes of support (30). Regarding the program settings, two programs were delivered in clinical settings $(27,30)$, two in the community $(23,28)$, two online $(24-26)$ and one in schools (29).

Salvatore (2010) presented a mixed mode peer support program within a psychiatric hospital (30). It was offered to patients of the hospital and their families. The hospital employed two peer support staff to deliver one-on-one peer support, group support as well as community education activities. While this program has been implemented as part of the Montgomery County Emergency Service, evaluation data on its effectiveness has yet to be published. The second program designed for patients in clinical settings was the Peers for Valued Life (PREVAIL) program (27). This program is a one-on-one support service for people who had attempted suicide and were patients of a psychiatric ward. Patients were teamed up with a peer specialist with lived experience of suicide and weekly meetings were held for up to 12 weeks after discharge from the ward. Peer specialists received training on risk assessment, using suicide prevention tools, communication and relationship building and motivational interviewing. In situations of acute risk clinicians were contacted. The aim of this program was to reduce suicide risk post-discharge from a psychiatric ward. 
The two community-based suicide prevention programs were designed to provide support to those in crisis or experiencing suicidal ideation. Firstly, the Alternatives to Suicide program (USA) runs peer support groups for people experiencing suicidality (23). Open group discussions are facilitated by trained peer supporters to enable conversations around the reasons and factors that may have contributed to someone wanting to die. Reflective of the key principles of Validation, Curiosity, Vulnerability and Community the conversations are non-judgemental and free of boundaries. Groups provide a safe and comfortable space to talk and focus on offering a non-clinical environment to build trust. Secondly, the Peer CARE Companion Program (Australia) offered through the Way Back Support Service is a new program which is currently being trialled $(28,31,32)$. It is directed at supporting people with a lived experience of suicide (experiencing a suicidal crisis or after a suicide attempt) in one-on-one peer support settings. The program was developed through a collaboration between three mental health organisations in Australia (Beyond Blue, New Horizons and Roses in the Ocean). Two trials and a consultation process including people with lived experience in 2017 and 2018 led to a revision of the program and the results of a second trial are yet to be released.

Two programs were set online using data from online messaging boards (24-26). Both aimed at better understanding the benefits and risks of participation to people experiencing suicidality by looking at the effect that using online messaging boards has on participants. These online interventions are best described as group support interventions, yet due to their open entry characteristic they allow both people with lived experience and non-suicidal people to participate. The content is participant/online user driven with limited control for quality and safety for people at risk.

Finally, a school-based program aimed at early detection of at-risk youth in Chinese schools, offered peer group support sessions led by students and supported by teachers and the school community (29). Students at risk were identified by peers or teachers and invited to participate in student-led support groups that met regularly. Teachers visited the groups monthly to help address any issues if needed. Group membership was voluntary and group leadership rotated. Group members were taught how to recognise unhappy and depressive behaviour in peers. Group leaders reported to the teacher and were able to refer students further if concerned.

With the exception of the school-based peer support program, which broadened its scope to include mood, depression and self-esteem as early warning indicators of suicidality, all programs were specifically aimed at supporting people with a lived experience of suicide.

\section{Effectiveness of suicide prevention peer support programs}

Four of the seven identified programs contained evaluation data; two were quantitative studies (23-25), one was qualitative (26) and one applied mixed-methods (27) (see Table 1).

The Alternatives to Suicide program reported early findings from internal feedback surveys with attendees of the support groups (23). Findings indicate that attending the groups was perceived as helpful as 
participants felt that they could talk freely about their experiences. Attending the groups had improved at least one area in attendees' lives. Areas of greatest improvement were increased sense of community and a better understanding of why suicidal thoughts may come up.

The Pilot Randomised Controlled Trial of the PREVAIL program demonstrated adequate fidelity of the peer support sessions in administering a conversation on belongingness, hope and safety and general support skills. Interviews with participants further showed positive ratings for the peer specialists' ability to relate, listen and advise, and provide specific support during the sessions. Due to the small sample size in this pilot trial, group comparisons could not be conducted and therefore no information on the effectiveness of the program to reduce suicidality in participants is available (27).

Kral (2006) and Eichenberg (2006) found that participation in online peer support forums decreased the intensity of suicidal thoughts $(24,25)$. The authors collected data from participants of the online forums via an online survey. Thirty-one percent of participants self-reported a decrease in intensity of suicidal thoughts as a result of their participation in the messaging boards. While $22 \%$ of respondents said they were more motivated to seek professional help, using suicide messaging boards did not increase helpseeking outside the forums. The main motivation for using online forums was for emotional support, to feel understood and receive comforting reactions.

In a qualitative analysis of threads from a suicide online forum Niederkrotenthaler and colleagues (2016) found that participation in this forum can help to improve a person's suicidality (26). The authors downloaded threads from seven pre-identified suicide message boards and thematically analysed a random selection of these threads. Several communicative strategies were associated with psychological improvements in online forum participants; these were receiving constructive advice, being actively listened to, receiving sympathy for one's struggle, and provision of alternatives to suicide by other members of the forum.

\section{Discussion}

Peer-led programs are increasingly common in mental health settings in addition to conventional clinical care and they are also an alternative support option for people in the community. While there is evidence for the effectiveness of peer support programs for people with severe mental illness and also for people bereaved by suicide $(13,16)$, our scoping review shows that research on peer-led support programs with a focus on suicidality is currently still in its infancy and therefore warrants further research attention.

This study is the first systematic scoping review of published literature on peer support programs for people experiencing suicidality. We identified 8 records accounting for 7 programs that focussed on peerled support programs in suicide prevention. The 7 eligible programs employed a range of different designs and included a variety of settings (schools, communities, rural and online). Only four programs provided evaluation data, and this data was basic and descriptive. This small number of eligible programs highlights a general scarcity of peer-led suicide prevention programs and data available on 
their effectiveness to reduce suicidality. Still, the little data available indicates some positive and promising results for peer support in suicide prevention.

Our findings hint at the potential for a positive function of the online environment as a support hub for people with lived experience of suicide and the potential for increased research for peer support in this setting. However, we identified an evidence gap for peer-led community-based suicide prevention programs and their effectiveness to reduce suicidality. On an exciting note, our consultations with experts suggests there are signs for new peer-led community-based peer support programs to be developed and future evaluations of some of these programs are planned. The pilot trial of the PREVAIL peer support program shows that it is possible and feasible to integrate peer support into the care program for people who experience suicidality, yet formal evaluation of these kinds of programs is needed to determine their effectiveness to reduce suicidality (27).

The potential for peer-led support in suicide prevention has increasingly been acknowledged by policy makers (33) and this creates momentum for service delivery. We anticipate that this positive development in terms of practice-driven changes will continue to expand our knowledge and understanding of suicide prevention.

\section{Challenges and limitations}

Upon screening of the literature, we identified that many records were not eligible because they did not include peers with lived experience of suicide. Eighty-four records were excluded in the full-text review stage due to either not providing enough information on the nature of the lived experience of peer supporters or because lived experience was defined more broadly and not specific to suicidality.

Further, we found that in some programs the definition of peers was not aligned with our selection criteria. In particular, school-based programs working with students tend to select peers on the basis of age or belonging to the same social group but did not make suicidal experiences part of the condition for becoming a peer supporter $(34,35)$. Some programs also described their intervention as peer group support, yet the group was led by a health professional (36). Others had a peer supporter as co-facilitator alongside a leading health professional, therefore not qualifying as a peer-led program (37). Finally, a few programs included peer support components within a larger program but did not report separately on the peer support component. These studies could therefore not be included in this review as the effect of the peer support component could not be determined.

While considerable work has been done on defining peer support and lived experience in the context of suicide prevention in recent years $(2,38)$, the findings from this review highlight that authors follow different definitions for peer support and often fail to provide adequate detail in the description of their program what constitutes peer support in their respective program. We often found that little information was provided regarding the involvement and characteristics of peer support workers. For example, it was frequently unclear if a peer support program was in fact peer-led or led by a clinician, and when the 
program was peer-led it did not specify if the peer supporter had lived experience of suicide or whether this was defined more broadly in the context of mental health. It is possible that the lack of information provided in the description of what constitutes peer support within a program may have led to the exclusion of otherwise eligible programs during the screening process of this review. This constitutes a limitation for understanding the nature of peer support within existing programs and ultimately affects what implications we can draw from existing literature on the effectiveness of peer-led support programs.

Our search also identified a considerable number of programs that focussed on training and capacity building in suicide prevention (e.g., awareness raising, suicide literacy or gate-keeper training programs) in the wider community. As per our selection criteria these programs were not eligible for this review, however they warrant a special mention as they help to describe where the field of peer-led suicide prevention is currently at. While lived experience is a crucial part of peer-led support, it has been widely recognised that adequate training and key competencies are crucial to ensure adequate support can be provided and to keep peer support workers safe $(38,39)$. Capacity building in the community therefore poses an important first step to build the foundation for the implementation of peer-led suicide prevention programs. Following the increased effort in capacity building we foresee a continued and sustained commitment to implementing peer-led support programs in the future and hopefully these will then be formally evaluated to build the evidence base in this field.

\section{Implications for future research, policy and practice}

To advance knowledge on peer support programs in suicide prevention we suggest a few areas for future investment. Firstly, the development of a framework for standard reporting on peer support initiatives would greatly improve our understanding of the breadth and depth of current peer support programs (40). In addition, improved quality of reporting on peer support roles in suicide prevention programs would help to clarify the underlying definition of peer support. Secondly, we need high-quality evaluations of peer support suicide prevention programs and of peer-led components within larger programs to better understand their effectiveness on participant health across different settings and delivery modes and to allow for comprehensive systematic reviews and meta-analysis in the future. This evidence can help enhance our efforts to better integrate peer-led support with conventional crisis support and find mutual benefit in both. Thirdly, while peer support is generally accepted as a positive addition to care by legislative bodies, we currently lack models for the efficient and effective integration of these programs alongside conventional care $(41,42)$. Addressing this issue would facilitate peer support to become a care component in its own merit. Finally, it has been widely recognised that adequate training and key competencies of peers are crucial to ensure adequate support can be provided in a safe and appropriate manner (38). Yet no accredited and standardised training exists for peer support workers in suicide prevention and should be developed to increase consistency and quality of support delivery.

It should also be noted what is already known about the positive effects of peer-led support in other related areas. While the knowledge is scarce on peer-led suicide prevention programs, it could be

Page 10/20 
beneficial to revisit evidence from mental health peer support and investigate whether similar approaches could be adapted to suicide prevention. This practical approach could then be subject to further testing and refining to cater to specific needs in suicide prevention.

\section{Conclusion}

While peer support programs are seeing greater support in the community, in health care and by policy makers, very little is known about their effectiveness in the context of suicide prevention. In this scoping review we identified very few peer-led support programs for suicide prevention and even fewer evaluations. The programs available today vary in approach, setting, and definitional clarity. While being descriptive, the few evaluations that were done showed some promising results. To improve our understanding of effective peer-led support programs in suicide prevention we encourage greater clarity in the reporting of key program characteristics and components and highlight the need for formal program evaluation. This will assist in creating a vital evidence base to inform future program development and implementation.

\section{Declarations}

Ethical approval and consent to participate: Not applicable.

Consent for publication: Not applicable.

Availability of data and materials: All data generated or analysed during this study are included in this published article and its supplementary information files. The literature compiled through this search is available through publications and the internet.

Competing interests: The authors declare no conflict of interest with respect to the research, authorship or publication of this article.

Funding: This study was supported through funding from the Australian Government Department of Health.

Author's contributions: AM designed the study in consultation with LR, MS and IO. AM and MS finalised the search terms, conducted the search and screened entries from academic literature databases. MS carried out the search and screening of Google Scholar entries. LR carried out the search and screening of entries from the WHO Clinical Trials Registry. IO searched websites and consulted with content experts in the field, whilst discussing findings with MS, AM and LR. MS compiled the charting table, summarised the findings, and drafted the manuscript. All authors contributed to revisions of the draft and approved the final version of the manuscript.

Acknowledgements: We would like to acknowledge the support of the National Leadership in Suicide Prevention Research Project, led by Prof. Jane Pirkis at the Centre for Mental Health, the University of 
Melbourne, and its Steering Group members who provided valuable feedback on this review.

\section{References}

1.Barnet I. Peer Support in Practice - A Research Report with Recommendations for Practice. online; 2018.

2.Mead S, Hilton D, Curtis L. Peer support: A theoretical perspective. Psychiatric rehabilitation journal. 2001;25(2):134.

3.Davidson L, Bellamy C, Guy K, Miller R. Peer support among persons with severe mental illnesses: a review of evidence and experience. World psychiatry. 2012;11(2):123-8.

4.Sokol R, Fisher E. Peer support for the hardly reached: a systematic review. American journal of public health. 2016;106(7):e1-e8.

5.Weiner DB. The apprenticeship of Philippe Pinel: a new document," observations of Citizen Pussin on the insane.". The American Journal of Psychiatry. 1979;36:1128-34.

6.Stratford AC, Halpin M, Phillips K, Skerritt F, Beales A, Cheng V, et al. The growth of peer support: an international charter. Journal of Mental Health. 2017:1-6.

7.Chamberlin J. On our own: Patient-controlled alternatives to the mental health system. New York: McGraw-Hill; 1978.

8.Department of Health, Commonwealth of Australia. The Fifth National Mental Health and Suicide Prevention Plan. 2017. Report No.: 11g26.

9.Repper J, Carter T. Using personal experience to support others with similar difficulties.

Together/University of Nottingham/NSUN www together-uk org/wpcontent/uploads/downloads/2011/11/usingpersexperience pdf. 2010.

10.United Nations. Convention on the Rights of Persons with Disabilities (CRPD) New York, USA: United Nations; 2006 [Available from: https://www.un.org/development/desa/disabilities/convention-on-therights-of-persons-with-disabilities.html.

11.Bellamy C, Schmutte T, Davidson L. An update on the growing evidence base for peer support. Mental Health and Social Inclusion. 2017;21(3):161-7.

12.Fuhr DC, Salisbury TT, De Silva MJ, Atif N, van Ginneken N, Rahman A, et al. Effectiveness of peerdelivered interventions for severe mental illness and depression on clinical and psychosocial outcomes: a systematic review and meta-analysis. Social psychiatry and psychiatric epidemiology. 2014;49(11):1691-702. 
13.Lloyd-Evans B, Mayo-Wilson E, Harrison B, Istead H, Brown E, Pilling S, et al. A systematic review and meta-analysis of randomised controlled trials of peer support for people with severe mental illness. BMC psychiatry. 2014;14(1):39.

14.Repper J, Carter T. A review of the literature on peer support in mental health services. Journal of mental health. 2011;20(4):392-411.

15.Andriessen K, Krysinska K, Hill NT, Reifels L, Robinson J, Reavley N, et al. Effectiveness of interventions for people bereaved through suicide: a systematic review of controlled studies of grief, psychosocial and suicide-related outcomes. BMC psychiatry. 2019;19(1):49.

16.Bartone PT, Bartone JV, Violanti JM, Gileno ZM. Peer support services for bereaved survivors: a systematic review. OMEGA-Journal of Death and Dying. 2017:0030222817728204.

17.Linde K, Treml J, Steinig J, Nagl M, Kersting A. Grief interventions for people bereaved by suicide: A systematic review. PloS one. 2017;12(6):e0179496.

18.Arksey H, O’Malley L. Scoping studies: towards a methodological framework. International journal of social research methodology. 2005;8(1):19-32.

19.Levac D, Colquhoun H, O’Brien KK. Scoping studies: advancing the methodology. Implementation science. 2010;5(1):69.

20.Moher D, Liberati A, Tetzlaff J, Altman DG. Preferred reporting items for systematic reviews and metaanalyses: the PRISMA statement. Annals of internal medicine. 2009;151(4):264-9.

21.Roper C, Grey F, Cadogan E. Co-production-putting principles into practice in mental health contexts. 2018. Melbourne: University of Melbourne; 2018.

22.Pinfold V, Szymczynska P, Hamilton S, Peacocke R, Dean S, Clewett N, et al. Co-production in mental health research: reflections from the people study. Mental Health Review Journal. 2015;20(4):220-31.

23.Davidow S, Mazel-Carlton C. Alternatives to Suicide. unpublished manuscript, retrieved from the authors2018.

24.Eichenberg C, Otte TA, Fischer G. Suizidselbsthilfe-Foren im Internet: Eine Befragungsstudie. Zeitschrift für klinische Psychologie und Psychotherapie. 2006;35(1):30-8.

25.Kral G. Online communities for mutual help: Fears, fiction, and facts. In: Murero M, Rice RE, editors. The Internet and health care: Theory, research, and practice. 1st Edition. New Jersey: Lawrence Erlbaum Associates; 2006. p. 215-32.

26.Niederkrotenthaler T, Gould M, Sonneck G, Stack S, Till B. Predictors of psychological improvement on non-professional suicide message boards: content analysis. Psychological medicine. 2016;46(16):3429- 
27.Pfeiffer PN, King C, Ilgen M, Ganoczy D, Clive R, Garlick J, et al. Development and pilot study of a suicide prevention intervention delivered by peer support specialists. Psychological Services. 2019;16:360-71.

28.Edwards B. The Way Back Support Service - Peer Care Companion Program. personal communication2018.

29.John W, Bagley C, Hoi-Wah M. Preventing suicidal behaviour in Chinese youth: The role of peer counselling. Suicidal Behaviour, Bereavement and Death Education in Chinese Adolescents: Hong Kong Studies: Routledge; 2018. p. 25-37.

30.Salvatore T. Peer specialists can prevent suicides: properly trained peers play a vital role in regional suicide prevention effort. Behavioral healthcare. 2010;30(9):31-3.

31.Beyond Blue. Support after suicide attempt [Available from: https://www.beyondblue.org.au/thefacts/suicide-prevention/after-a-suicide-attempt/support-after-a-suicide-attempt.

32.Roses in the Ocean. Peer Care Companions [Available from: https://rosesintheocean.com.au/peercare-companions/.

33.U.S. Department of Health and Human Services (HHS) Office of the Surgeon General and National Action Alliance for Suicide Prevention. 2012 National Strategy for Suicide Prevention: goals and objectives for action. Washington DC: US Department of Health \& Human Services; 2012.

34.Wright-Berryman J, Hudnall G, Hopkins R, Bledsoe C. Hope squads: Peer-to-peer suicide prevention in schools. Children \& Schools. 2018;40(2):125-6.

35.Pickering TA, Wyman PA, Schmeelk-Cone K, Hartley C, Valente TW, Pisani AR, et al. Diffusion of a peerled suicide preventive intervention through school-based student peer and adult networks. Frontiers in psychiatry. 2018;9:598.

36.Smith D. CADS: Carer and depression support group.. Australian Journal of Primary Health. 2006;12(3):9-11.

37.Hom MA, Davis L, Joiner TE. Survivors of suicide attempts (SOSA) support group: Preliminary findings from an open-label trial. Psychological services. 2018;15(3):289.

38.Daniels AS, Bergeson S, Fricks L, Ashenden P, Powell I. Pillars of peer support: Advancing the role of peer support specialists in promoting recovery. The Journal of mental health training, education and practice. 2012;7(2):60-9. 
39.Meagher J, Stratford AC, Jackson F, Jayakody E, Fong T. Peer Work in Australia. A new future for Mental Health Mind Australia \& Flourish Australia; 2018.

40.Dennis C-L. Peer support within a health care context: a concept analysis. International journal of nursing studies. 2003;40(3):321-32.

41.Beales A, Wilson J. Peer support-the what, why, who, how and now. The Journal of Mental Health Training, Education and Practice. 2015;10(5):314-24.

42.Klee A, Chinman M, Kearney L. Peer specialist services: New frontiers and new roles. Psychological Services. 2019;16(3):353.

\section{Tables}

Table 1: Description of included studies 


\begin{tabular}{|c|c|c|c|c|}
\hline $\begin{array}{l}\text { Reference; Program } \\
\text { title; Country }\end{array}$ & $\begin{array}{l}\text { Program description (setting, } \\
\text { modality, lived experience etc.) }\end{array}$ & $\begin{array}{l}\text { Study aim and } \\
\text { methodology }\end{array}$ & $\begin{array}{l}\text { Sample characteristics } \\
\text { (where relevant) }\end{array}$ & Key findings (where relevant) \\
\hline $\begin{array}{l}\text { Reference: } 24 ; 25 \\
\text { Title: } \\
\text { Selbstmordforum.de } \\
\text { Country: Germany }\end{array}$ & $\begin{array}{l}\text { Setting: Online messaging } \\
\text { boards (forums); Modality: } \\
\text { Group support; } \\
\text { Target group: Users of online } \\
\text { suicide forum } \\
\text { Lived experience: } 88 \% \text { of study } \\
\text { participants reported suicide } \\
\text { ideation; } 54 \% \text { of participants } \\
\text { had made at least one suicide } \\
\text { attempt in their life. } 28 \% \text { had } \\
\text { suicidal thoughts for the first } \\
\text { time } 1-3 \text { years ago; } 34 \% \text { had } \\
\text { suicidal thoughts more than } 5 \\
\text { years ago for the first time; } \\
12 \% \text { never had suicidal } \\
\text { thoughts. }\end{array}$ & $\begin{array}{l}\text { Aim: Investigate } \\
\text { whether the use of } \\
\text { online suicide } \\
\text { message boards is } \\
\text { harmful or beneficial } \\
\text { to people with } \\
\text { suicidality. } \\
\text { Methodology: } \\
\text { Quantitative cross- } \\
\text { sectional study; } \\
\text { Convenience sample; } \\
\text { online questionnaire } \\
\text { of people using the } \\
\text { online suicide } \\
\text { message board } \\
\text { "selbstmordforum.de"; } \\
\text { Analysis of users' } \\
\text { socio-demographic } \\
\text { characteristics, their } \\
\text { motivations for } \\
\text { participation, what } \\
\text { content they shared, } \\
\text { and what effect } \\
\text { participation in online } \\
\text { suicide messaging } \\
\text { boards had on } \\
\text { participants }\end{array}$ & $\begin{array}{l}164 \text { participants; } 50 \% \text { male, } \\
50 \% \text { female; sample biased } \\
\text { to young adults with } 59 \% \\
\text { under } 21 \text { years and } 88 \% \\
\text { under } 30 \text { years; } 80 \% \text { single; } \\
67 \% \text { students or in higher } \\
\text { education settings }\end{array}$ & $\begin{array}{l}\text { Online suicide forums do show } \\
\text { signs of support and } \\
\text { constructive help through } \\
\text { conversations with other } \\
\text { people with lived experience. } \\
\text { Decrease in intensity of } \\
\text { suicidal thoughts during the } \\
\text { respondents' participation in } \\
\text { the suicide forum; } 31 \% \text { of } \\
\text { participants say the decrease } \\
\text { is due to their participation. } \\
\text { Participation does not seem to } \\
\text { increase help-seeking. Only } \\
22 \% \text { of respondents said they } \\
\text { were more motivated to seek } \\
\text { help. } \\
\text { Motivation to use the forum } \\
\text { was feeling understood and } \\
\text { receiving comforting } \\
\text { reactions. }\end{array}$ \\
\hline $\begin{array}{l}\text { Reference: } 26 \\
\text { Title: Suicide } \\
\text { messaging boards } \\
\text { Country: } \\
\text { Germany/Austria }\end{array}$ & $\begin{array}{l}\text { Setting: Online messaging } \\
\text { boards (forums); Modality: } \\
\text { Group support; } \\
\text { Target group: Users of online } \\
\text { suicide messaging boards } \\
\text { Lived experience: Suicidality of } \\
\text { the online user was coded } \\
\text { according to the content in the } \\
\text { comments on the messaging } \\
\text { board. }\end{array}$ & $\begin{array}{l}\text { Aim: Identifying } \\
\text { communication } \\
\text { patterns that can be } \\
\text { used to improve } \\
\text { suicidality of } \\
\text { participants on online } \\
\text { suicide message } \\
\text { boards. } \\
\text { Methodology: } \\
\text { Qualitative study; } \\
\text { Secondary data } \\
\text { analysis of a random } \\
\text { selection of threads } \\
\text { from } 7 \text { pre-identified } \\
\text { suicide message } \\
\text { boards (online forum); } \\
\text { Thematic analysis of } \\
\text { threads }\end{array}$ & $\begin{array}{l}401 \text { threads from anti- } \\
\text { suicide boards, } 382 \text { threads } \\
\text { from neutral boards; } 399 \\
\text { threads from pro-suicide } \\
\text { boards }\end{array}$ & $\begin{array}{l}\text { Constructive advice, active } \\
\text { listening, collaborative } \\
\text { problem solving, expression of } \\
\text { sympathy, debunking the } \\
\text { suicide myths, and provision of } \\
\text { alternatives to suicide and } \\
\text { positive stories of lived } \\
\text { experience help to improve a } \\
\text { participant's suicidality. }\end{array}$ \\
\hline $\begin{array}{l}\text { Reference: } 30 \\
\text { Program: } \\
\text { Montgomery County } \\
\text { Emergency Service - } \\
\text { Peer specialist }\end{array}$ & $\begin{array}{l}\text { Setting: Hospital, patient care; } \\
\text { Modality: Mixed mode, } \\
\text { including one-on-one peer } \\
\text { support; two part-time peer } \\
\text { specialists provide services to } \\
\text { in-patients, families and }\end{array}$ & $\begin{array}{l}\text { Aim: Description of } \\
\text { suicide prevention } \\
\text { service within a } \\
\text { hospital - in-patient } \\
\text { care }\end{array}$ & N/A. & N/A. \\
\hline
\end{tabular}




\begin{tabular}{|c|c|c|c|c|}
\hline $\begin{array}{l}\text { support } \\
\text { Country: USA }\end{array}$ & $\begin{array}{l}\text { community members } \\
\text { including support groups, one- } \\
\text { on-one counseling, training and } \\
\text { capacity building in the } \\
\text { community. } \\
\text { Target group: Patients of a } \\
\text { psychiatric hospital and } \\
\text { people in crisis support } \\
\text { Lived experience: Peer } \\
\text { specialists have past } \\
\text { experience of suicide and } \\
\text { received peer support and } \\
\text { recovery training. }\end{array}$ & & & \\
\hline $\begin{array}{l}\text { Reference: } 29 \\
\text { Program: Health } \\
\text { Intervention Training } \\
\text { - Mutual Aid } \\
\text { Network (HIT-MAN) } \\
\text { Country: China }\end{array}$ & $\begin{array}{l}\text { Setting: Schools; } \\
\text { Modality: Peer group support } \\
\text { based on a social network } \\
\text { approach; Objectives are to } \\
\text { encourage students to support } \\
\text { and, in some cases, refer their } \\
\text { friends who have been thinking } \\
\text { about suicide or showing very } \\
\text { poor self-esteem and signs of } \\
\text { depression to a trusted adult } \\
\text { (who will also be part of the } \\
\text { HIT-MAN training network). } \\
\text { Target group: School students } \\
\text { (adolescents), teachers and } \\
\text { school communities } \\
\text { Lived experience: Students in } \\
\text { peer groups have lived } \\
\text { experience of mental health } \\
\text { problems which are seen as } \\
\text { early warning signs of the } \\
\text { trajectory to suicide. }\end{array}$ & $\begin{array}{l}\text { Aim: Description of a } \\
\text { suicide prevention } \\
\text { program that helps } \\
\text { students to identify } \\
\text { problems of extreme } \\
\text { stress, anxiety and } \\
\text { suicidal feelings in } \\
\text { their peers, including } \\
\text { training and peer } \\
\text { support groups. }\end{array}$ & N/A. & N/A. \\
\hline $\begin{array}{l}\text { Reference: } 27 \\
\text { Program: Peers for } \\
\text { Valued Living } \\
\text { (PREVAIL) } \\
\text { Country: USA }\end{array}$ & $\begin{array}{l}\text { Setting: Inpatient psychiatric } \\
\text { unit and post discharge care } \\
\text { Modality: One-on-one peer } \\
\text { support; Peer specialists first } \\
\text { meet patients in inpatient unit } \\
\text { and then provide support for } \\
12 \text { weeks after discharge (max } \\
16 \text { meetings); flexible meeting } \\
\text { arrangements (frequency and } \\
\text { duration); } \\
\text { Target group: Patients } \\
\text { admitted to an inpatient } \\
\text { psychiatry due to suicidality } \\
\text { Lived experience: Peer } \\
\text { specialists had lived } \\
\text { experience of serious suicidal } \\
\text { thoughts or behaviour. }\end{array}$ & $\begin{array}{l}\text { Aim: Development and } \\
\text { pilot testing of a peer } \\
\text { specialist intervention } \\
\text { to reduce suicide risk, } \\
\text { Methodology: Pilot } \\
\text { randomised controlled } \\
\text { trial; randomisation of } \\
\text { participants to normal } \\
\text { care and PREVAIL } \\
\text { peer support } \\
\text { intervention; } \\
\text { Semi-structured } \\
\text { interviews to capture } \\
\text { participant } \\
\text { experiences and } \\
\text { feedback }\end{array}$ & $\begin{array}{l}70 \text { adult patients (age } 18 \text { or } \\
\text { older) from two inpatient } \\
\text { psychiatric units; patients } \\
\text { had to have history of } \\
\text { suicidal ideation or } \\
\text { attempt; patients were } \\
\text { excluded from participation } \\
\text { if they showed unstable } \\
\text { psychosis, cognitive } \\
\text { impairment, severe } \\
\text { personality disorder, } \\
\text { invasive therapy. } 34 \text { were } \\
\text { allocated to the peer } \\
\text { support arm and } 36 \\
\text { received usual care. }\end{array}$ & $\begin{array}{l}\text { Fidelity was rated for } 20 \text { peer } \\
\text { support sessions; } 85 \% \text { of the } \\
\text { peer specialist sessions } \\
\text { demonstrated adequate fidelity } \\
\text { to administering a } \\
\text { conversation tool regarding } \\
\text { hope, belongingness, or safety; } \\
72.5 \% \text { of general support skills } \\
\text { (e.g., validation) were } \\
\text { performed with adequate } \\
\text { fidelity. } \\
\text { No intervention arm } \\
\text { comparisons due to small } \\
\text { sample; therefore, no data on } \\
\text { effectiveness to reduce } \\
\text { suicidality. } \\
\text { Participants' qualitative } \\
\text { responses were highly positive } \\
\text { regarding peer specialists' }\end{array}$ \\
\hline
\end{tabular}




\begin{tabular}{|c|c|c|c|c|}
\hline & & & & $\begin{array}{l}\text { ability to relate, listen, and } \\
\text { advise and to provide support } \\
\text { specifically during } \\
\text { discussions. }\end{array}$ \\
\hline $\begin{array}{l}\text { Reference: } 23 \\
\text { Program: } \\
\text { Alternatives to } \\
\text { Suicide through the } \\
\text { Western Mass } \\
\text { Recovery Learning } \\
\text { Community (RLC) } \\
\text { Country: USA }\end{array}$ & $\begin{array}{l}\text { Setting: Community led } \\
\text { intervention; Modality: Peer } \\
\text { support group for people who } \\
\text { experience suicidality; } \\
\text { underpinned by the key } \\
\text { principles of Validation + } \\
\text { Curiosity + Vulnerability + } \\
\text { Community; It creates } \\
\text { conditions that support } \\
\text { recovery at both the individual } \\
\text { and community level through } \\
\text { trauma-sensitive peer } \\
\text { supports and the development } \\
\text { of a regional network. } \\
\text { Target group: People who } \\
\text { experience suicidality (not } \\
\text { bereavement) } \\
\text { Lived experience: Peer support } \\
\text { groups are open to anyone } \\
\text { with lived experience of } \\
\text { suicidal thoughts or attempts; } \\
\text { Leaders who struggled with } \\
\text { thoughts of suicide or suicide } \\
\text { attempts and who wanted to } \\
\text { support others. }\end{array}$ & $\begin{array}{l}\text { Aim: Description of } \\
\text { the Alternative to } \\
\text { Suicide (ATS) peer } \\
\text { support program, an } \\
\text { innovative peer-led } \\
\text { suicide prevention } \\
\text { program from the } \\
\text { Western } \\
\text { Massachusetts } \\
\text { Recovery Learning } \\
\text { Community (RLC). } \\
\text { Methodology: Internal } \\
\text { feedback survey with } \\
\text { attendees of support } \\
\text { groups. }\end{array}$ & not available & $\begin{array}{l}\text { Early findings from an internal } \\
\text { feedback survey with } \\
\text { attendees of the support } \\
\text { groups: attendees felt most } \\
\text { strongly that attending the } \\
\text { groups was helpful because } \\
\text { they could talk freely; } \\
\text { attending had improved at } \\
\text { least one area in attendees' } \\
\text { lives; increased sense of } \\
\text { community and increased } \\
\text { understanding on why suicidal } \\
\text { thoughts may come up were } \\
\text { areas with greatest } \\
\text { improvement. }\end{array}$ \\
\hline $\begin{array}{l}\text { Reference: } 28 ; 31 ; 32 \\
\text { Program: The Way } \\
\text { Back Support } \\
\text { Service - Peer CARE } \\
\text { Companion Program } \\
\text { Country: Australia }\end{array}$ & $\begin{array}{l}\text { Setting: Community-based } \\
\text { intervention; Modality: One-on- } \\
\text { one support; } \\
\text { Target group: People with lived } \\
\text { experience of suicide (suicidal } \\
\text { crisis or after a suicide } \\
\text { attempt) } \\
\text { Lived experience: Peer support } \\
\text { is customised depending on } \\
\text { whether peers are to be } \\
\text { supporting people at risk. } \\
\text { Lived experience of the peer } \\
\text { care companion will be } \\
\text { matched with the person in } \\
\text { need. }\end{array}$ & $\begin{array}{l}\text { Aim: Description of } \\
\text { the Peer CARE } \\
\text { Companion program } \\
\text { which provides peer } \\
\text { support to people with } \\
\text { lived experience of } \\
\text { suicide or bereaved by } \\
\text { suicide. }\end{array}$ & N/A. & N/A. \\
\hline
\end{tabular}

\section{Figures}




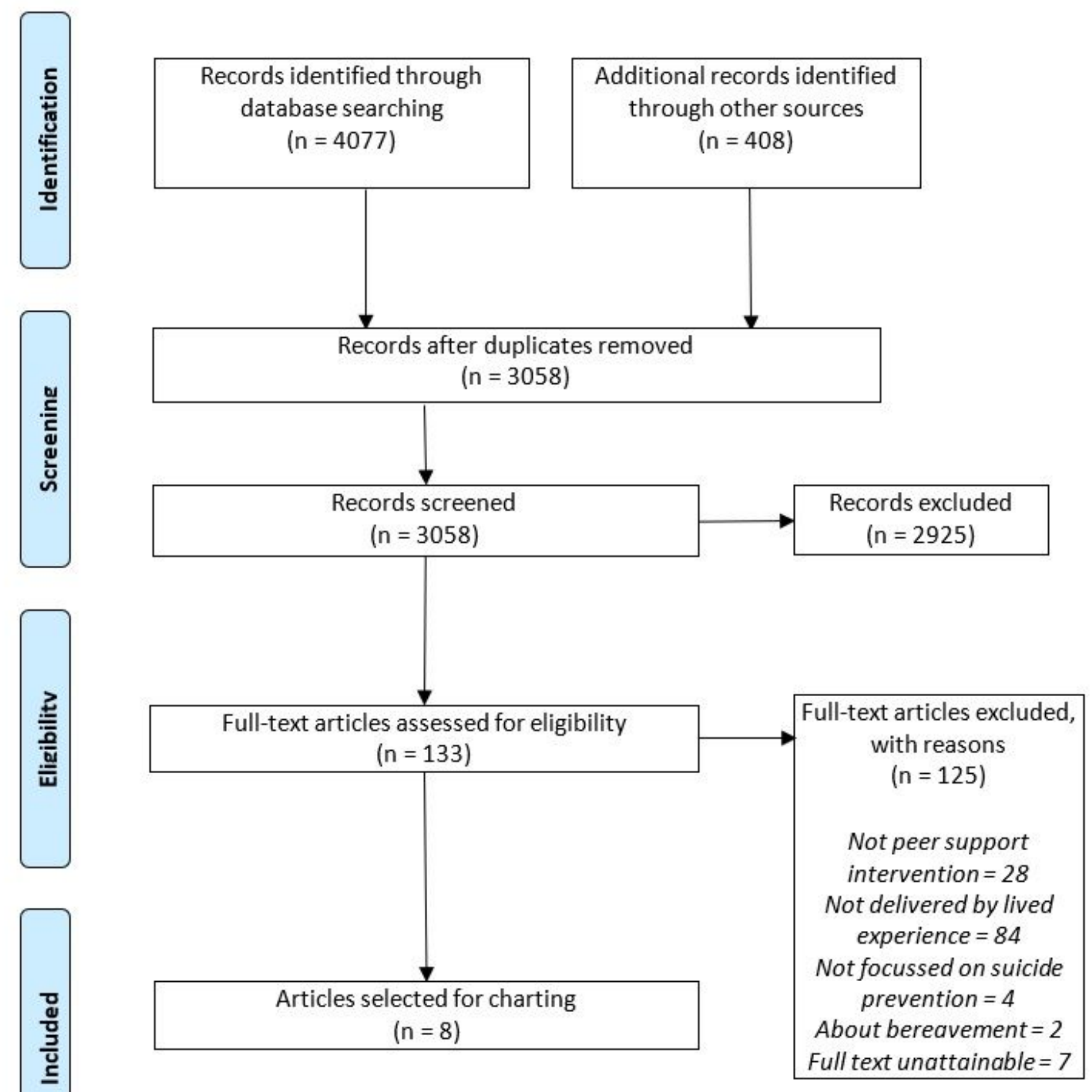

Figure 1

Flow diagram illustrating the literature search process

\section{Supplementary Files}

This is a list of supplementary files associated with this preprint. Click to download. 
- Additionalfile1.docx

- Additionalfile2.docx 